\title{
Configure Routing Path Algorithms for Ethernet Topology
}

\author{
R. Idayathulla, K Saravanan
}

\begin{abstract}
The multiplication of different associated stages, including the "Internet of Thing" [1], Control frameworks (ICS), associated vehicles and on-board arranges have brought about the concurrent utilization of various conventions and gadgets. Disorderly circumstances brought about by the utilization of various conventions and various kinds of gadgets, for example, heterogeneous systems, executed diversely by merchants, make it hard to receive an adaptable security arrangement, as late examinations on Intruder Detection Systems (IDS) in light of profound learning. These examinations advanced the profound learning model for their condition to improve execution, however the essential rule of the profound learning model utilized was unaltered, so it tends to be called cutting edge IDS with a model that has not many or no necessities. A few investigations have proposed IDS dependent on unaided learning innovation that doesn't require named information. In any case, not utilizing accessible assets, for example, organize parcel information, is a misuse of assets. In the event that the security arrangement considers the job and significance of the gadgets that make up the system and the standard convention security zone by specialists, the benefits can be utilized well, however they will not, at this point be adaptable. A large portion of the IDS examines dependent on profound learning models have utilized "Recurrent Neural Networks"[1] (RNN), which is a regulated learning model, in light of the fact that the attributes of the RNN model, particularly while consolidating memory long haul (LSTM), are better designed to mirror the progression of parcel information goes after some time and accordingly perform improved than other directed learning models, for example, convolutional neural system (CNN). Geography result may be an essential necessity for a few system the executives and investigating assignments the greater part of our systems nowadays incorporate neighborhood. In PC systems ascertaining procedures, exchange data with each other using associations information joins between centers. A distant way bearing discovering system in information systems decides the most straightforward way for information parcels established on space. Some far off way runs likewise yield into thought organize inactivity and different highlights that impact dissemination on a specific course.
\end{abstract}

Keywords: $A^{*}$ Search Algorithm, Dijkstra's Algorithm, Ethernet, IP Addresses, Link State Algorithm, Network Infrastructure, Name and Network Management, Internetwork Design Study

Revised Manuscript Received on August 15, 2020.

* Correspondence Author

R. Idayathulla, Research Scholar, Department of Computer Science, "Ponnaiyah Ramajayam Institute of Science \& Technology (Deemed to be University), Thanjavur”, India. E-mail: idayathulla86@gmail.com

Dr K Saravanan*, Dean, Faculty of Computer Science, "Ponnaiyah Ramajayam Institute of Science \& Technology (Deemed to be University), Thanjavur", India. E-mail: ks_tnj@yahoo.co.in

(C) The Authors. Published by Blue Eyes Intelligence Engineering and Sciences Publication (BEIESP). This is an open access article under the CC BY-NC-ND license (http://creativecommons.org/licenses/by-nc-nd/4.0/)

\section{INTRODUCTION}

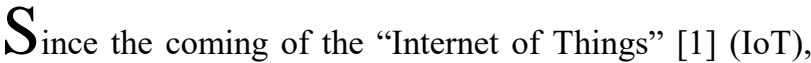
various stages have been advertised. For instance, the modern control framework (ICS) is slowly developing towards keen and independent frameworks. In the field of ICS, the idea of mechanical (IoT) in light of IoT has been proposed. The IoT speaks with different sensors and oversees basic framework and has a bigger system scale than existing frameworks. For Industry 4.0 Germany proposed a vigilant circumstance to enliven the headway of ICS; Currently, thoughts, for instance, wise urban territories and adroit preparing plants are getting continuously express and sensible. Remote Sensor Networks (WSNs) are now and again remunerated as a significant part of the IoT like a work mastermind. Regardless of whether or not WSN is a bit of IoT, it is treated as a segment of IoT in light of the information that distinctive sensor devices combine in WSN to make a framework. The biological system where systems are worked with IoT gadgets around man-made reasoning (AI) speakers additionally has comparative attributes. Man-made intelligence speaker biological systems are likewise being read for security innovations, for example, computerized legal sciences [2]. There are starting at now a plausible 40,000,000 hosts associated with the Internet. The quick development in the significance of the Internet is for the most part a effect of the "Overall Web"[3] (WWW) and educate systems which permit free arrangement of information. A smart gander at the authentic setting of the Internet and its improvement grants you to grasp the reason behind its conspicuousness and, possibly, anticipate some example in future frameworks organization. "During the 1960s and 1970s" [2], various systems utilized their own conventions and usage. The trading of data between these systems immediately turned into an issue and a typical convention must be created. The "Protection Advanced Research Projects Agency"[3] (DARPA) support the looking,

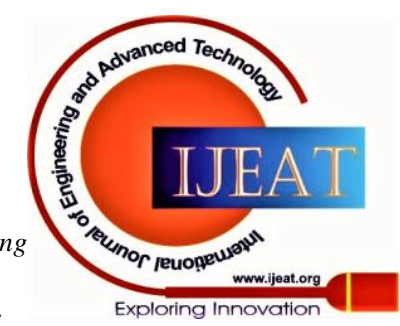




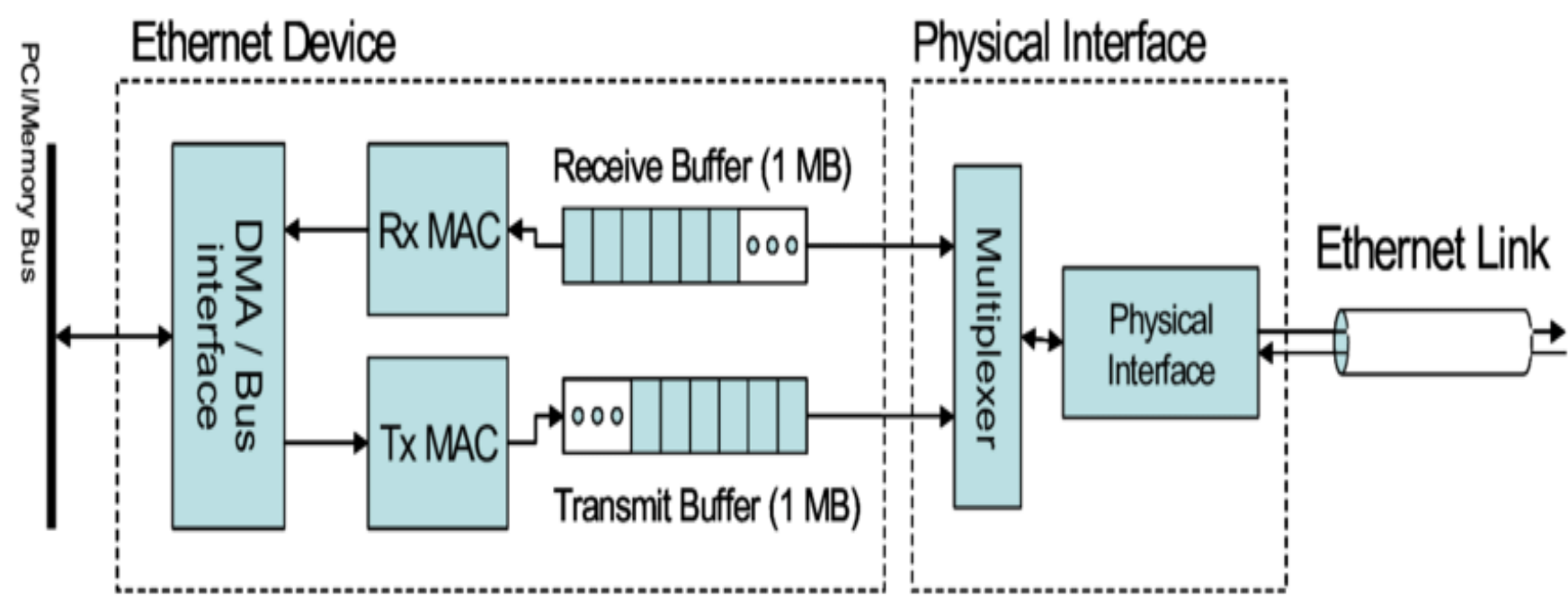

Fig. 1. Block Diagram of Ethernet.

of this "regular convention and the ARPANET protocol"[3] suite, which presented the fundamental thought of layering. The TCP/IP convention suite at that point advanced from the ARPANET convention suite and took its shape in 1978. With the utilization of TCP/IP, a system was made which was fundamentally utilized by government offices and exploration organizations with the end goal of data sharing and examination. joint effort. "In the mid 1980s"[3], TCP/IP turned into the essential convention for multi-merchant systems, for example, ARPANET, NFSNET, and local systems. The arrangement of conventions was it was incorporated into "the University of California"[3], Berkeley's UNIX working framework and made accessible to people in general for an alleged installment. Starting there on, TCP/IP turned out to be generally utilized because of its low accessibility on UNIX and its spread to other working frameworks.

Today, TCP/IP offers organizations the capacity to blend distinctive physical systems while giving clients a typical arrangement of capacities. It permits interoperability between hardware gave by various merchants on numerous stages and gives Internet get to.

The present Internet is made up"[3] of huge worldwide, national, and local spines that permit grounds and neighborhood systems and people to get to worldwide assets. Web use has become exponentially in the course of recent years, particularly with the selection of the shopper showcase. Guiding in a PC framework implies the activity of finding a course from the source center point to the objective center. Given an immense framework, more likely than not, there is more than one course for each source-objective pair. The endeavor of a coordinating estimation is to find the least cost route among each and every open course for a particular source-objective pair. There are two sorts of guiding calculations used today on the Internet, which are the association Link State directing Algorithm and the separation vector controlling Algorithm [4]. The "IEEE 802.3" [1] standard is commonly called as Ethernet. It is a vehicle based impart associate with decentralized control. It

can work at $10 \mathrm{Mbps}$ or $100 \mathrm{Mbps}$ or above. PCs on an Ethernet can communicate at whatever point they have to do accordingly. If at any rate two machines send simultaneously, by then their bundles sway. By then the communicating PCs just keep it together for an optional time and retransmit their sign. There are various advances available in the LAN grandstand yet the most standard one of them is Ethernet [4].

\section{NEED FOR DESIGN IN IP NETWORKS}

Lying on the sour chance that you don't take the example to plan your "arrange, the straightforwardness of" [3] interconnection] utilizing TCP/IP can cause issues. The motivation behind this book is to feature a portion of the issues and feature the kinds of choices you should make when considering executing a TCP/IP arrangement.

For instance, an absence of compelling system address arranging can cause genuine constraints on the "quantity of hosts" [3], you can cling to your system. Need of focal association can bring about substitution source "names and addresses"[3], which can keep you from interconnecting confined systems. Address irregularities can keep you from interfacing with the Internet, and other potential issues can incorporate the powerlessness to make an interpretation of asset names to asset addresses in light of the fact that no association has been set up between the name workers. A few issues that emerge from an inadequately planned or spontaneous system are anything but difficult to fix. A few, be that as it may, take a ton of "time and effort"[3] to fix. Envision physically arranging each host in a system of 3000 hosts in light of the truth that the picked tending to conspire no longer addresses the issues of a business! "while face with the task of structuring another TCP/IP "arrange or permit realistic systems to interconnect"[3], a few significant plan issues should be address"[3]. For instance, how to dole out addresses to arrange assets, how to change existing locations, utilize static or dynamic steering, how to design your name workers and how to secure your system are: All the inquiries that should be replied. Simultaneously, issues of unwavering

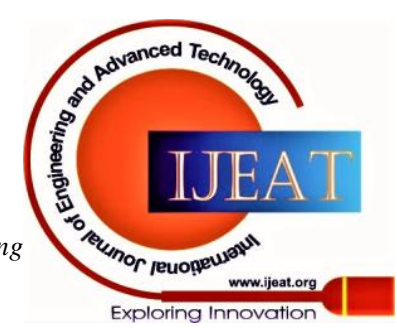




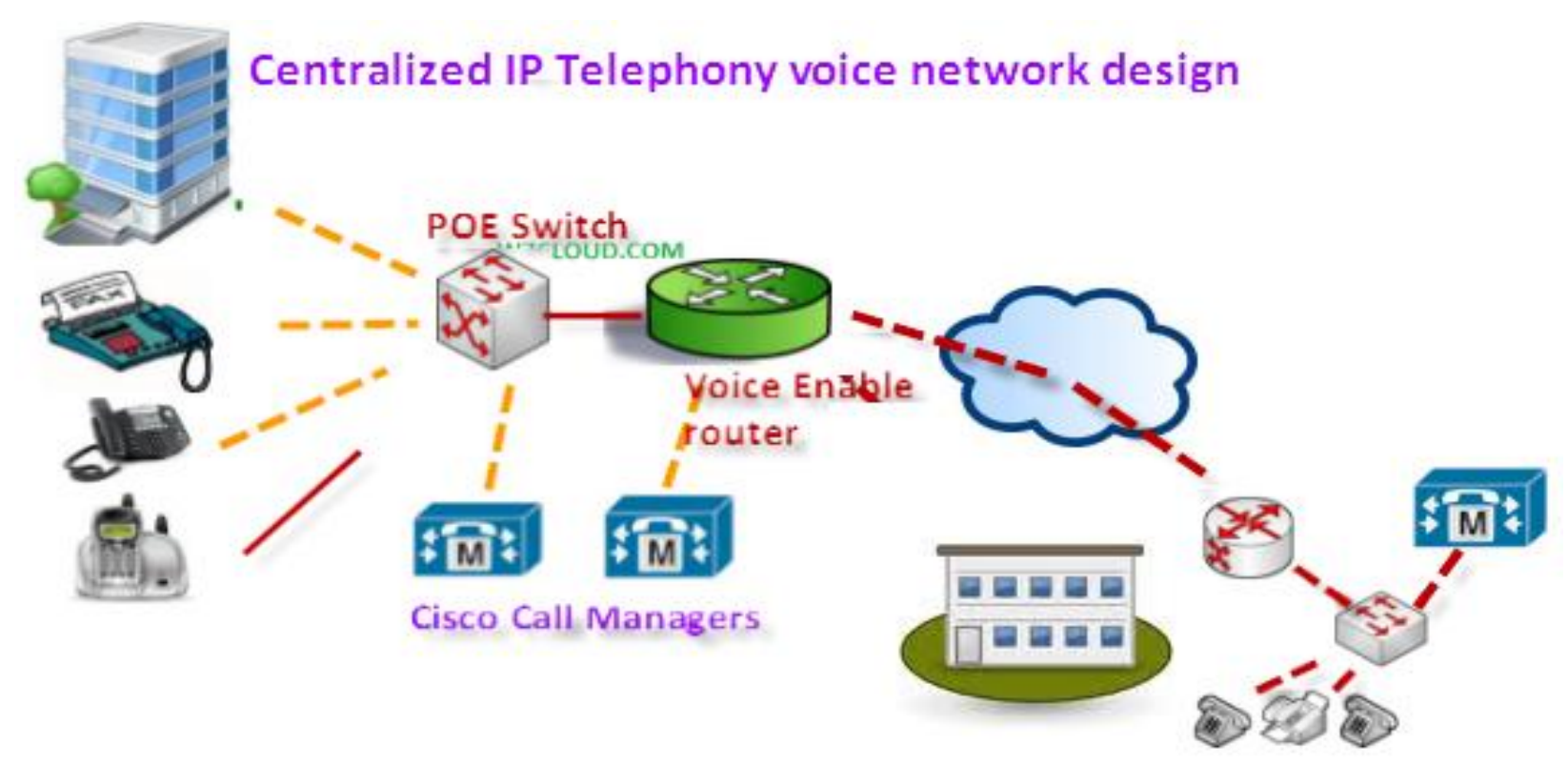

Fig. 2. Design in IP Networks.

quality, accessibility and bolster must be thought of, just as how you will oversee and deal with your system. The accompanying parts will address these and different concerns and furnish you with the data you have to settle on your choices. any place likely, we will offer general guideline for structuring IP organizes somewhat than examine creation or stage explicit contemplations. "This is on the grounds that much of the time the item explicit documentation as of now exists and gives the subtleties expected to arrangement and deployment"[3]. We won't endeavor to break down TCP/IP applications top to bottom as the data is likewise accessible to you in different archives [3].Anomaly discovery innovation has been as of late urbanized because of the start of the ideas of profound information and neural system (NN). These advancement have been powerfully intentional in ICS systems. "More exploration is being done on IoT associated systems, aside from cases utilizing managed learning models like CNN are significantly less productive than half breed (counting semi-directed) or unverified model since Monitored models require troublesome assets, for example, [1] exact marks Electronics 2020, 9, 11514 of 15 and unusual information. Be that as it may, NNs concentrated with adequate information assets to give, for example, names and parities, for the most part have the most elevated precision when checked. CNN was once in a while utilized in IDS between managed models at times. A few cases have utilized CNN for include extraction or programmed coding rather than as the essential classifier on the grounds that CNN is brilliant at identifying and removing spatiotemporal highlights from information. A few investigations made the IDS basically utilizing CNN, yet the subsequent execution was more regrettable than in different examinations. To viably improve a CNN for IDS, the information must be intended to adequately mirror the significance of the piece. Since CNNs work proficiently on convolutional highlights, for example, pictures, the use of system bundles as an information stream is of no outcome [1].Author (s) can send paper in the given email address of the diary. There are two email address. It is mandatory to send paper in both email address.

\section{A. Casing Relay Network}

Casing Relay is a bundle exchanged innovation offered as a media transmission administration via transporters and long stretch administrators, basically utilized for WAN connections. Casing hand-off have the option to be utilized to sum up "neighborhood (LAN)" traffic, for example, [5] Ethernet outlines for correspondence in overabundance of computerized information transmission "lines for "wide territory systems (WANs)", and have the option to associate different "LANs" to frame" [5] one Multipoint WAN. Edge hand-off innovation was initially a part of Integrated Communication Digital Network (ISDN) advanced correspondence innovation.

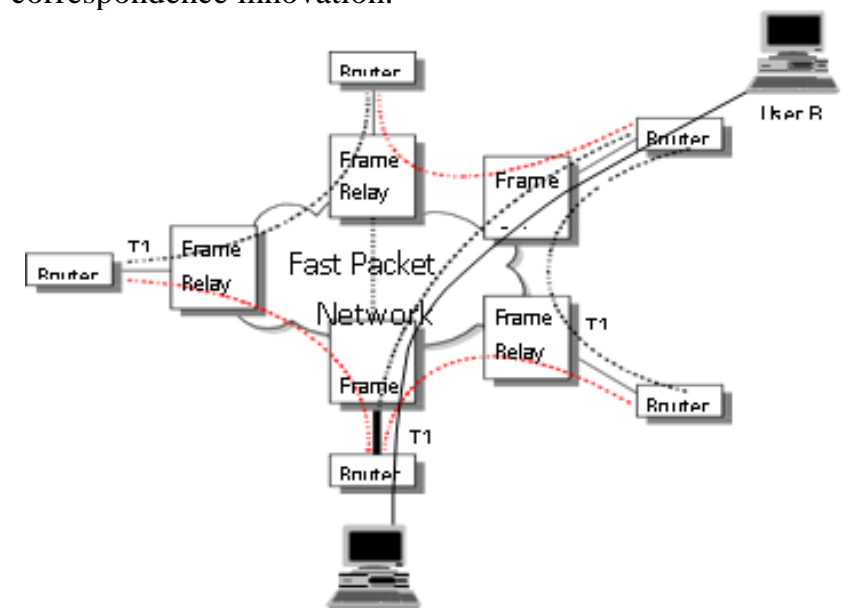

Fig. 3. Casing Relay Network.

There are three significant ideas in Frame Relay that you ought to know about:

- "Information Link Connection Identifier" (DLCI)

DLCI resembles the comparable MAC address in a LAN situation. The information is exemplified by the switch in Frame Relay outlines and conveyed over the DLCI based system.

Published By: Blue Eyes Intelligence Engineering and Sciences Publication (C) Copyright: All rights reserved.

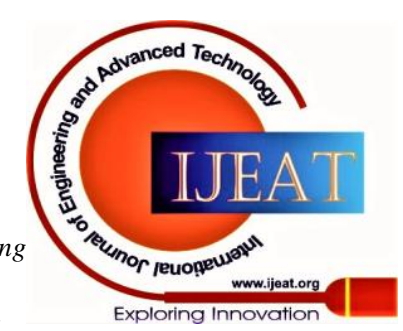




\section{Configure Routing Path Algorithms for Ethernet Topology}

DLCI can have nearby or worldwide significance, the two of which extraordinarily distinguish a correspondence channel. Traffic to or from every one of the related end stations is multiplexed, conveying distinctive DLCIs, over a similar client organize interface. The system utilizes DLCI to connect a casing with a particular virtual circuit. The location field is two, three or four bytes in length. The default Frame Relay address field utilized by most usage is a two-byte field. The DLCI is a multi-bit field of the "address field" and the length of which relies upon the "length of the location field".

•" Permanent virtual circuits" (PVC)

PVCs are predefined courses through the "Edge Relay arrange" that associate two end frameworks to one another. These are intelligent courses on the system distinguished locally by the DLCIs. As a component of a membership choice, PVC transfer speed is pre-dispensed and charges apply paying little mind to the volume of traffic.

- "Virtual exchanged circuits" (SVC)

In contrast to PVCs, SVCs are not for all time characterized in the "Edge Relay organize". The associated terminal gear may demand a call arrangement when it is important to send information. A few choices identified with transmission, are indicated while arranging the association. SVCs are actuated by terminal hardware, for example, switches associated with Frame Relay systems, and the charges applied by an open Frame Relay administrator depend on circuit exercises and are not quite the same as PVCs. It is fascinating to see that, despite the fact that it is viewed as a non-transmission arrange, Frame Relay bolsters the ARP convention and the have a break of the TCP/IP steering conventions [3].

\section{III. “A* SEARCH ALGORITHM" [5]}

"A* search calculation" is single of the most astounding and most famous methods used to discover courses and guide ways. Casually, A * search calculations, in contrast to other traversal strategies, have "cerebrums". This implies it is actually a keen calculation that isolates it from other regular calculations. This reality is explained in detail in the following areas. Furthermore, it's additionally worth referencing that a ton of online games and cards utilize this calculation "to locate the briefest way" productively (estimation).

\section{A. "Algorithm" [5]}

1. Introduce the open rundown

2. Introduce the blocked rundown

uncover the underlying hub

show (you can disappear your $\mathrm{f}$ at 0 )

3. for whatever length of time that the open rundown isn't unfilled

a) discover the hub with the littlest $f$ in

open rundown, call it "q"

b) leave $q$ from the discharge list

c) make 8 replacements of $q$ and build up its

guardians to what

d) for every replacement

I) if the objective is the replacement, stop the hunt

"successor.g = q dab g +" separation interfacing

replacement and q successor.h = separation from focus to replacement (This protect be finished utilizing various conventions, we will talk about 3 heuristics: "Manhattan, askew and Euclidean Heuristic") "successor.f = replacement dab g + replacement spot h"

ii) if a hub with a similar situation as

the replacement is in the discharge list which has a f not as much as replacement, preclude this replacement

iii) if a hub with a similar situation as the replacement is in the blocked rundown which has a f second rate compared to the replacement, exclude this relative in any case put in the hub to the discharge list

end (for circle)

e) press $q$ in the shut rundown end (while circle) [6].

\section{IV. "DIJKSTRAS ALGORITHM" [6]}

Dijkstra's calculation (or "Dijkstra's Shortest Path First" [5] calculation, SPF algorithm) is a calculation for finding the briefest ways between hubs in a chart, which may speak to, for instance, street systems. "It was brought about by PC researcher Edsger W. Dijkstra in 1956 and distributed three years later. The calculation exists in numerous variations" [5]. Dijkstra's unique calculation found the most limited way between two given nodes,however a progressively normal variation fixes a solitary hub as the "source" hub and finds briefest ways as of the "source" [6] to every single other hub in the diagram, creating a most brief way tree.

For a given source hub in the chart, the calculation finds the most brief way between that hub and each other. It can likewise be utilized for finding the most brief ways from a solitary hub to a solitary goal hub by halting the calculation once the most brief way to the goal hub has been resolved. For instance, if the hubs of the diagram speak to urban areas and edge way costs speak to driving separations between sets of urban communities associated by an immediate street (for effortlessness, disregard red lights, stop signs, expressways and different impediments), Dijkstra's calculation can be utilized to locate the most limited course between one city and every single other city. A generally utilized utilization of briefest way calculation is organize directing conventions, most outstandingly IS-IS (Intermediate System to Intermediate System) and Open Shortest Path First (OSPF). It is likewise utilized as a subroutine in different calculations, for example, Johnson's.

\section{A. "Algorithm" [6]}

Engraving all center points unvisited. Make a great deal of all the unvisited centers called the unvisited set. Dispense to every center a temporary division regard: set it to zero for our fundamental center point and to boundlessness for each other center point. Set the fundamental center point as current.

For the current center point, consider the aggregate of its unvisited neighbors and figure their temporary partitions through the current center point. Differentiation the as of late decided theoretical division with the current selected regard and designate the humbler one. For example, if the current center An is separate with a partition of 6 , and the edge interfacing it with a neighbor $\mathrm{B}$ has length 2 , by then the detachment to B through A will be $6+2=8$. If $\mathrm{B}$ was as of late set apart with a partition more critical than 8 , by then change it to 8 .

Published By:

Blue Eyes Intelligence Engineering and Sciences Publication (C) Copyright: All rights reserved.

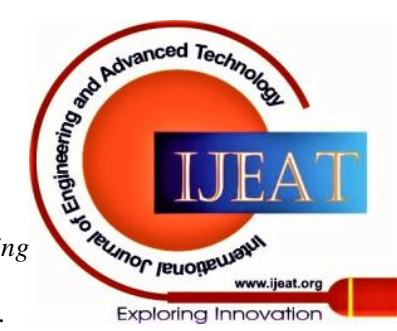



when we are done considering the total of the unvisited neighbors of the current center, mark the current center point as visited and oust it from the unvisited set. A visited center will never be checked again. In case the objective center has been checked visited (when masterminding a course between two unequivocal centers) or if the most diminutive temporary partition among the centers in the unvisited set is endlessness (when organizing an absolute traversal; happens when there is no relationship between the hidden center point and remaining unvisited centers), by then stop. The computation has wrapped up.

Something different, select the unvisited center that is separate with the humblest restrictive division, set it as the new "current center point", and come back to organize 3 [7].

\section{LINK STATE ROUTING PROTOCOL}

Association state controlling shows are one of the two guideline classes of coordinating shows used in group trading frameworks for PC correspondences, the other being detachment vector directing shows. Examples of association state coordinating shows fuse Open "Shortest Path First" (OSPF) [5] and middle System to in-between System (IS-IS). The association state show is performed by each trading center point in the framework (i.e., center points that are set up to propel groups; in the Internet, these are called switches). The major thought of association state controlling is that every center point constructs a guide of the accessibility to the framework, as an outline, exhibiting which centers are related with which various centers. Each center point by then unreservedly calculates the accompanying best reasonable route from it to each possible objective in the framework. Each variety of most ideal ways will by then structure each center's directing table.

This shows up distinctively comparable to isolate vector coordinating shows, which work by having each center point share its controlling table with its neighbors, in an association state show the fundamental information went between centers is accessibility related. Association state counts are now and again portrayed coolly as each switch, "illuminating the world with respect to its neighbors [8].

\section{A. "Algorithm" [8]}

$\mathrm{C}(\mathrm{i}, \mathrm{j})$ : cost of the connection of nodule $\mathrm{i}$ to $\mathrm{j}$. " If nodes $\mathrm{i}$ and j" [1] don' t seem to be " directly connected, then c (i, j) $=\infty " \quad[1]$

D (r): defines the cost of the path from source code to destination $\mathrm{v}$ which currently has the least cost.

$\mathrm{P}(\mathrm{r})$ : defines the previous node (near of $\mathrm{v}$ ) together with the current minimum cost way from the origin to $\mathrm{v}$.

$\mathrm{N}$ : is that the total range of nodes obtainable within the network.

initialization

For all hubs $\mathrm{V}$

in the event that $r$ neighboring $A$

henceforth $\mathrm{D}(\mathrm{r})=\mathrm{c}(\mathrm{A}, \mathrm{r})$

additionally $\mathrm{D}(\mathrm{r})=$ boundless

circle

discovers $\mathrm{w}$ not in $\mathrm{N}$ to such an extent that $\mathrm{D}(\mathrm{r})=$ least.

Enhance w to N
Something different, the current worth will be kept. Right

$\mathrm{N}=\{\mathrm{A}\} / / \mathrm{A}$ is a main node.

Update D (r) for all adjacent $\mathrm{v}$ and not $\mathrm{N}$ :

$\mathrm{D}(\mathrm{r})=\min (\mathrm{D}(\mathrm{r}), \mathrm{D}(\mathrm{w})$ Add c $(\mathrm{w}, \mathrm{r}))$

Until all the nodes in $\mathrm{N}$

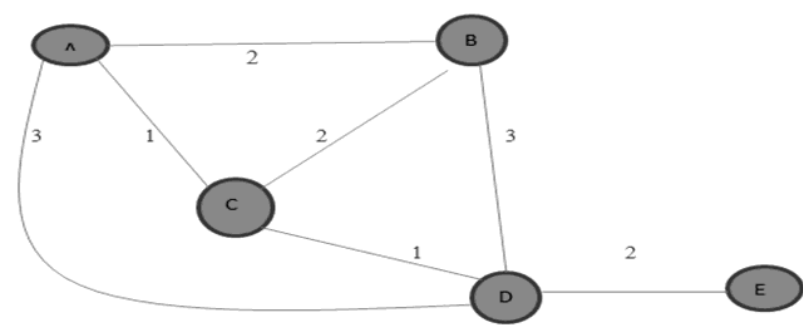

Fig. 4. Source Vertex is A.

In the overhead diagram, source vertex is A

The initial step is an introduction step. The least cost way as of now known from A to its legitimately associated neighbors, $\mathrm{B}, \mathrm{C}, \mathrm{D}$ is 2,1,3 individually. The expense from $\mathrm{A}$ to $\mathrm{B}$ is set to 2 , from $A$ to $D$ is set to 3 and from $A$ to $C$ is set to 1 . The expense from $A$ to $E$ is set to unendingness since they are not legitimately associated with $\mathrm{A}$.

Table- I: Initial Table

\begin{tabular}{|l|l|c|c|c|c|}
\hline Step & $\mathbf{N}$ & $\mathbf{D}(\mathbf{B}), \mathbf{P}(\mathbf{B})$ & $\mathbf{D}(\mathbf{C}), \mathbf{P}(\mathbf{C})$ & $\mathbf{D}(\mathbf{D}), \mathbf{P}(\mathbf{D})$ & $\mathbf{D}(\mathbf{E}), \mathbf{P}(\mathbf{E})$ \\
\hline 1 & $\mathrm{~A}$ & $2 \mathrm{~A}$ & $1 \mathrm{~A}$ & $3 \mathrm{~A}$ & $\alpha$ \\
\hline
\end{tabular}

"Step 2" [1]

"In the table" [1] above, we observe that the vertex $\mathrm{C}$ has the minimum cost way "in step 1" [1]. So, it is new to N. Now, we must determine a minimum cost way through vertex $\mathrm{C}$.

(a) Calculative shortest way from A to B

$\mathrm{v}=\mathrm{B}, \mathrm{w}=\mathrm{C}$

$\mathrm{D}(\mathrm{B})=\min (\mathrm{D}(\mathrm{B}), \mathrm{D}(\mathrm{C})+\mathrm{C}(\mathrm{C}, \mathrm{B}))$

$=\min (2,1+2)>$

$=\min (2,3)$

The minimum value is 2 . Therefore, the presently shortest wayafter A to B is two.

(b) Calculative shortest way from $\mathrm{A}$ to $\mathrm{C}$

$\mathrm{v}=\mathrm{C}, \mathrm{w}=\mathrm{C}$

$\mathrm{D}(\mathrm{C})=\min (\mathrm{D}(\mathrm{C}), \mathrm{D}(\mathrm{C})+\mathrm{c}(\mathrm{C}, \mathrm{C}))$

$=\min (1,1+0)$

$=\min (1,1)$

The minimum value is 1 . Therefore, the presently shortest way after $A$ to $C$ is 1 .

(c) Calculative shortest way from A to D

$\mathrm{v}=\mathrm{D}, \mathrm{w}=\mathrm{C}$

$\mathrm{D}(\mathrm{D})=\min (\mathrm{D}(\mathrm{D}), \mathrm{D}(\mathrm{C})+\mathrm{c}(\mathrm{C}, \mathrm{D}))$

$=\min (3,1+1)$

$=\min (3,2)$

The minimum value is 2 . Therefore, the presently shortest way from A to D is 2 .

Step 3

In the table overhead, we note that togetherD and $\mathrm{B}$ have the least cost way in step 2. Consider the vertex D. Now, we tend to confirm the minimum cost way of the remaining vertices through D.

(a) Calculative the shortest wayafter A to B

$\mathrm{v}=\mathrm{B}, \mathrm{w}=\mathrm{D}$

$\mathrm{D}(\mathrm{B})=\min (\mathrm{D}(\mathrm{B}), \mathrm{D}(\mathrm{D})+\mathrm{c}(\mathrm{D}, \mathrm{B}))$

$=\min (2,3+3)$

$=\min (2,6)$

Published By:

Blue Eyes Intelligence Engineering 


\section{Configure Routing Path Algorithms for Ethernet Topology}

The minimum value is 2 . Therefore, the presently shortest way after A to B is 2 .

(b) Calculative the shortest way from $\mathrm{A}$ to $\mathrm{C}$ $\mathrm{v}=\mathrm{C}, \mathrm{w}=\mathrm{D}$

$\mathrm{D}(\mathrm{C})=\min (\mathrm{D}(\mathrm{C}), \mathrm{D}(\mathrm{D})+\mathrm{c}(\mathrm{D}, \mathrm{C}))$

$=\min (1,3+1)$

$=\min (1,4)$

The minimum value is 1 . Therefore, the presently shortest way after $\mathrm{A}$ to $\mathrm{C}$ is 1 .

(c) Calculative the shortest way after A to D $\mathrm{v}=\mathrm{D}, \mathrm{w}=\mathrm{D}$

$$
\begin{aligned}
& \mathrm{D}(\mathrm{D})=\min (\mathrm{D}(\mathrm{D}), \mathrm{D}(\mathrm{D})+\mathrm{c}(\mathrm{D}, \mathrm{D})) \\
& \quad=\min (3,3+0) \\
& \quad=\min (3,3)
\end{aligned}
$$

The minimum value is 3 . Therefore, the presently shortest way after A to D is 3 .

\section{Step 4}

we reminder that the apex $\mathrm{B}$ takes the minimum cost way in step 3. Therefore, it is new to N. Now, we tend to confirm the minimum cost way of the lasting apexes through $\mathrm{B}$.

(a) Calculative the shortest way after A to B $\mathrm{v}=\mathrm{B}, \mathrm{w}=\mathrm{B}$

$$
\begin{aligned}
& \mathrm{D}(\mathrm{B})=\min (\mathrm{D}(\mathrm{B}), \mathrm{D}(\mathrm{B})+\mathrm{c}(\mathrm{B}, \mathrm{B})) \\
& \quad=\min (2,2+0) \\
& \quad=\min (2,2)
\end{aligned}
$$

The minimum value is 2 . Therefore, the presently shortest way after A to B is 2 .

(b) Calculative the shortest wayafter $\mathrm{A}$ to $\mathrm{C}$ $\mathrm{v}=\mathrm{C}, \mathrm{w}=\mathrm{B}$

$$
\begin{aligned}
& \mathrm{D}(\mathrm{C})=\min (\mathrm{D}(\mathrm{C}), \mathrm{D}(\mathrm{C})+\mathrm{c}(\mathrm{B}, \mathrm{C})) \\
& \quad=\min (1,1+2) \\
& \quad=\min (1,3)
\end{aligned}
$$

The minimum value is 1 . Therefore, the presently shortest way after $\mathrm{A}$ to $\mathrm{C}$ is 1 .

(c) Calculative the shortest wayafter A to D

$\mathrm{v}=\mathrm{D}, \mathrm{w}=\mathrm{B}$

$$
\begin{aligned}
& \mathrm{D}(\mathrm{D})=\min (\mathrm{D}(\mathrm{D}), \mathrm{D}(\mathrm{D})+\mathrm{c}(\mathrm{B}, \mathrm{D})) \\
& \quad=\min (3,3+3) \\
& \quad=\min (3,6)
\end{aligned}
$$

"The minimum value is" [1] 3. Therefore, the presently shortest way after A to D is 3 .

(d)Calculative the shortest wayafter A to E $\mathrm{v}=\mathrm{E}, \mathrm{w}=\mathrm{B}$

$$
\begin{aligned}
& \mathrm{D}(\mathrm{E})=\min (\mathrm{D}(\mathrm{E}), \mathrm{D}(\mathrm{E})+\mathrm{c}(\mathrm{B}, \mathrm{E})) \\
& =\min (\alpha, \alpha+\alpha) \\
& \alpha
\end{aligned}
$$

Table- II: Final Table

\begin{tabular}{|c|c|c|c|c|c|}
\hline Step & $\mathbf{N}$ & $\mathbf{D}(\mathbf{B}), \mathbf{P}(\mathbf{B})$ & $\mathbf{D}(\mathbf{C}), \mathbf{P}(\mathbf{C})$ & $\mathbf{D}(\mathbf{D}), \mathbf{P}(\mathbf{D})$ & $\mathbf{D}(\mathbf{E}), \mathbf{P}(\mathbf{E})$ \\
\hline 1 & $\mathrm{~A}$ & $2 \mathrm{~A}$ & $1 \mathrm{~A}$ & $3 \mathrm{~A}$ & $\alpha$ \\
\hline 2 & $\mathrm{AC}$ & $2 \mathrm{~A}$ & $1 \mathrm{~A}$ & $2 \mathrm{C}$ & $\alpha$ \\
\hline 3 & $\mathrm{ACD}$ & $2 \mathrm{~A}$ & $1 \mathrm{~A}$ & $2 \mathrm{C}$ & $4 \mathrm{D}$ \\
\hline 4 & ACDB & $2 \mathrm{~A}$ & $1 \mathrm{~A}$ & $2 \mathrm{C}$ & $4 \mathrm{D}$ \\
\hline 5 & ACDBE & $2 \mathrm{~A}$ & $1 \mathrm{~A}$ & $2 \mathrm{C}$ & $4 \mathrm{D}$ \\
\hline
\end{tabular}

Step 5

In the table above, we observe that the final vertex is E. Therefore, it is new to $\mathrm{N}$. at the present, we conclude the minimum cost way of the lasting vertices through $\mathrm{E}$.

(a) Calculative the shortest way after A to $\mathrm{E}$ $\mathrm{v}=\mathrm{E}, \mathrm{w}=\mathrm{E}$

$\mathrm{D}(\mathrm{E})=\min (\mathrm{D}(\mathrm{E}), \mathrm{D}(\mathrm{E})+\mathrm{c}(\mathrm{E}, \mathrm{E}))$

$$
\begin{aligned}
& =\min (4,4+0) \\
& =\min (4,4)
\end{aligned}
$$

The minimum value is 4 . Therefore, the presently shortest way, since A to $\mathrm{E}$ is 4 .

\section{INTERNETWORK DESIGN STUDY}

The accessibility plan for such a framework is commonly fundamental, which is basically a traded Ethernet spine with shared access to the work zone. The fact of the matter is to come out with an arrangement that is both smart and cooked for future expansion, if basic. The cabling for the framework is the standard Categor- 5 UTP, moved in a modest PC room that has been changed over from a store room. All the interfacing devices, similarly as the specialist, are arranged inside that room. The printer is fixed by worked in "Ethernet ports" [1] and they are found alongside the customers.

The underlying advance is to perceive different social occasions of customers subject to PC resources requirements. For this circumstance, we separate customers into a power customer gathering and anon-power customer gathering. The power customer bundle will all in all be the real accomplices who need to print a lot of documentation, pull colossal chronicles from the laborer, or extra presentation records into the specialist. They will by and large use awesome quality PCs that come fitted with a 10/100 Mbps Ethernet card. The non-power customer bundles will all in all be administrative authorities who achieve progressively manual endeavors, for instance, taking note of calls and supporting authoritative work. They use the framework for the most part for examining email and doing some fundamental word dealing with. They will as a rule have lower-end PCs, or even utilized articles. The physical blueprint may take after the going with:

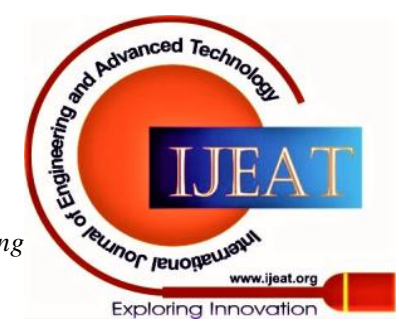




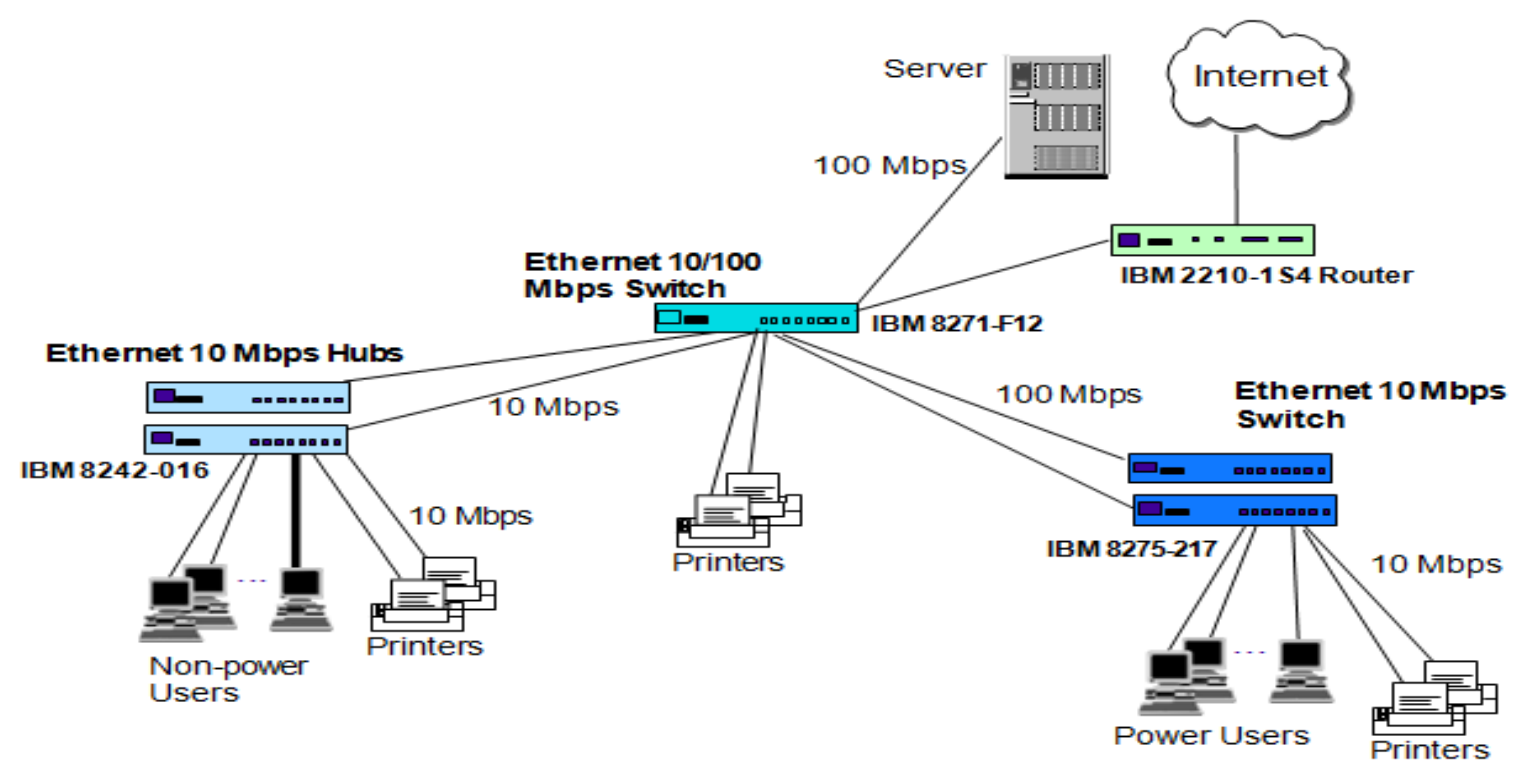

Fig. 5. Objective Diagram for a Small Network - Stage 1.

The purpose of secluding the customers into two social events is clearly to save cost. We can use a 10 Mbps focus point (IBM 8242-008) with an uplink, to interface the non-power customers to the framework. An inside point is reliably a not too bad gadget to center customers to a framework since it is humble and is more than acceptable to serve the non-power customers. The power customers can be related with the framework through a 10 Mbps Ethernet switch (IBM 8275-217) with an uplink, or authentically to the spine. The establishment of the framework is a " $10 / 100 \mathrm{Mbps}$ switch (IBM 8271-F12)" [2] so as to use to give uplink ports to the middle focuses, similarly as partner the specialist and printers. For relationship with the Internet, a little switch is required. "The IBM 2210 Nways" [2] switch is an average choice as it is down to earth and gives an ISDN relationship with the ISP. It is related with the framework with a $10 \mathrm{Mbps}$ Ethernet port. There is no requirement for the change to connect with the framework at 100 Mbps considering the way that the bottleneck is reliably the WAN association, partner at $64 \mathrm{Kbps}$ at the ISDN end, the $10 \mathrm{Mbps}$ Ethernet interface is all that might be required.

Notice that in this framework, the steadfastness of the framework is a ton of subject to the faithful nature of the equipment. In a framework like this, compose disillusionment is commonly realized by gear frustration. Thusly, it is fundamental to pick equipment from good producers. The IBM Ethernet switches are both monetarily shrewd and high gauge, so they are a superb choice for this framework.

The arrangement has furthermore thought about customer advancement. The spine switch gives a constraint of 12 ports and has spare ports for partner additional contraptions. The middle focuses and the 10 Mbps switches have spare ports for interfacing customers. The structure can in like manner cook for an expansive augmentation plan: the spine switch can be superseded with the IBM 8275-326 Ethernet switch, which gives 24 10/100 Mbps traded ports. With the extra furthest reaches of spine traded ports, more laborers and $10 \mathrm{Mbps}$ switches can be incorporated. With more ports available at the spine switch, a couple "exceptional" customers can truly be related truly at $100 \mathrm{Mbps}$ to the spine. The physical blueprint for the framework will look something like the going with [3].

Utilitarian social occasions subject to orchestrate division are direct in glow of the truth that frameworks basically interface contraptions together. How the different contraptions are related on the framework doubtlessly qualify those things that have a spot with an interconnected assembling and those that are stayed away from by an enforceable framework affiliation or conductor. Frameworks should be seen as both truly (what devices are related with various devices by methods for framework connections or distant affiliations) and reliably (what devices share the proportionate routable framework space, subnet or get the chance to control list).

Physical framework limits are definitely not hard to choose using a framework map. Ideally (in spite of the way that not taking everything into account), all control structure frameworks should have a hard physical breaking point as a unidirectional stream that shields traffic from entering an inexorably secure zone from a less secure one. Everything being equivalent, there will be interconnection centers involving a single association, in a perfect world through a firewall or possibly other defensive contraptions.

Astute framework limits are portrayed by the use of contraptions dealing with OSI Layer 3 (switches, impelled switches, firewalls) to separate a physical framework into different area spaces. These devices give a clever limit between every framework. This powers all trades beginning with one savvy framework then onto the close to encounter the Layer 3 contraption, where ACLs, rule sets, and other cautious measures can be completed.

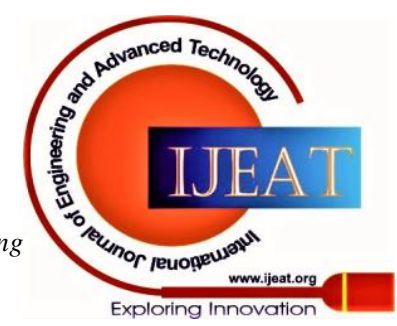




\section{Configure Routing Path Algorithms for Ethernet Topology}

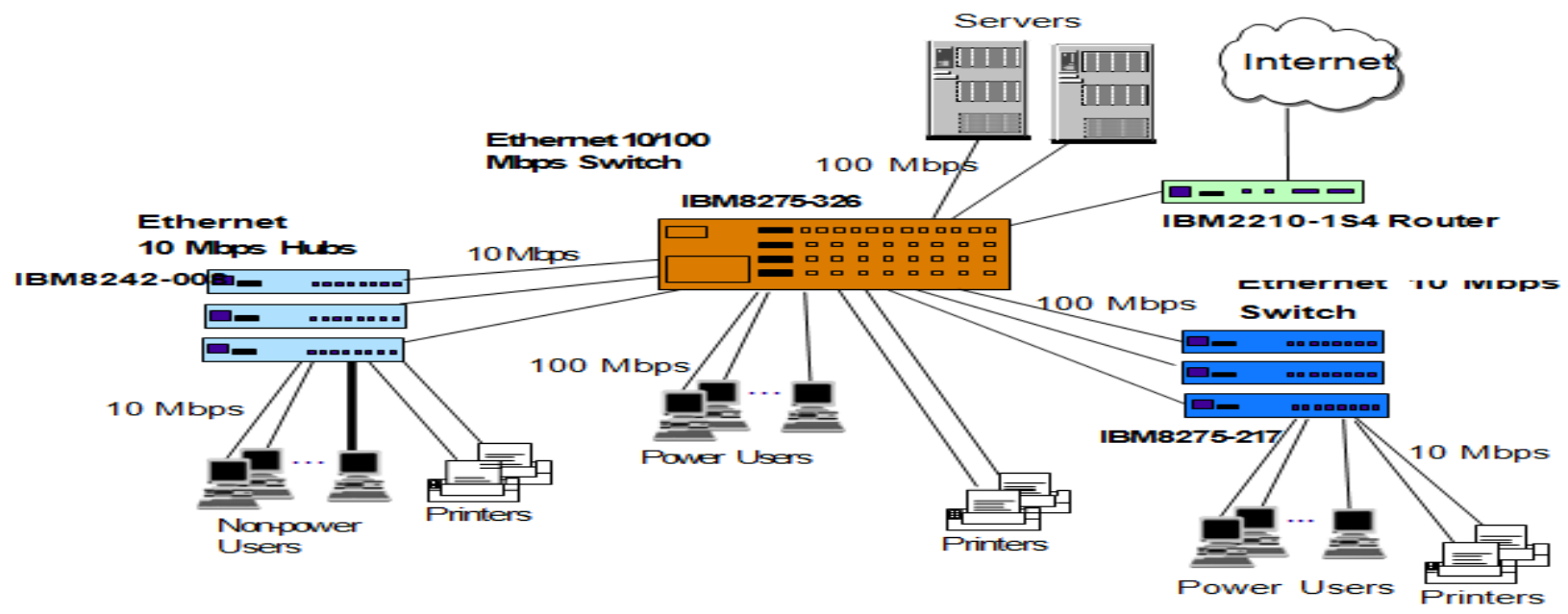

Fig. 6. Objective Diagram for a Small Network - Stage 2.

The plan, or geology, of a framework is basic to choosing its introduction. Framework geology is the way wherein a framework is sorted out, together with the substantial or reasonable depiction of how associations and center points are put up to transmit to each other.

There are different ways a framework can be engineered, all with different upsides and drawbacks, and some are more important in explicit conditions than others. Directors have an extent of decisions with respect to picking a framework geology, and this decision must record for the size and size of their business, its goals, and spending plan. A couple of endeavors go into convincing framework geology the administrators, including arrangement the officials, visual arranging, and general execution watching. The key is to fathom your goals and necessities to make and manage the framework topography in the right way for your business.

\section{VII. "LOGICAL NETWORK DESIGN" [4]}

The smart framework structure for an arrangement of this size is commonly a level framework and for our model, we have every device in a lone subnet because there is no security required with respect to get to. The keen framework arrangement is liberated from the physical accessibility, reflecting only the Layer 3 guide (IP map) of the framework, as portrayed in the going with outline.

The IP address used for the framework is reflected in the framework. Despite the way that there is only a solitary specialist in the framework, you can see that an extent of IP conveys has been consigned to the laborer. In an IP compose, especially the reasonable structure, it is reliably basic to believe in front, make game plans for expansion. The range given out to laborers suggests that we can concoct to 20 specialists later on. The reasons are proportionate to for printers and customers. Notice that the range gave food to a switch is significantly tinier when colossal framework, where a spine subnet is generally contained a huge amount of switches; by then the IP address task is remarkable. there is no prerequisite for certain switches, thusly we need not hold a significant range. A unique case is in a stood absent from the rest. Consistently for an arrangement of this size, appear in a dissimilar way in relative to the rest. Consistently for an arrangement of this size,

System graphs, both legitimate and physical, are vital to successful system and IT foundation the board. With state-of-the-art outlines, organize administrators can investigate (and limit personal time), plan for limit, dodge IT mess, look after programming, and keep the system secure and consistent. There are two fundamental kinds of system charts: physical and sensible. Physical system graphs (as is basic in DCIM programming) delineate the physical geography of the system and how the physical gadgets (or items) are associated.

As the data contained inside coherent system outlines relates to the "L3 (Layer 3) of the OSI model" [4]; L2 gadgets, (for example, switches) are not portrayed in a L3 or sensible system chart. While physical system outlines are significant, intelligent graphs make organize the board simpler in the accompanying manners:

Albeit a few systems truly dwell on a solitary dynamic center switch, organize traffic is isolated and made sure about utilizing static courses, ACLs, and VLANs. From a useful point of view, this is as secure as discrete individual switches.

IP Services

The accompanying subsections give a portrayal of some rising IP benefits that are frequently a significant part in a total system plan for a Sun ONE organization. The IP administrations are partitioned into two classes:

Stateful Session Based This class of IP administrations necessitates that the switch keep up meeting state data so a specific customer's meeting state is kept up over all bundles. This necessity has serious ramifications for profoundly accessible arrangements and cutoff points adaptability and execution.

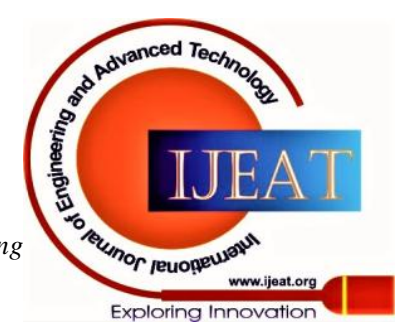




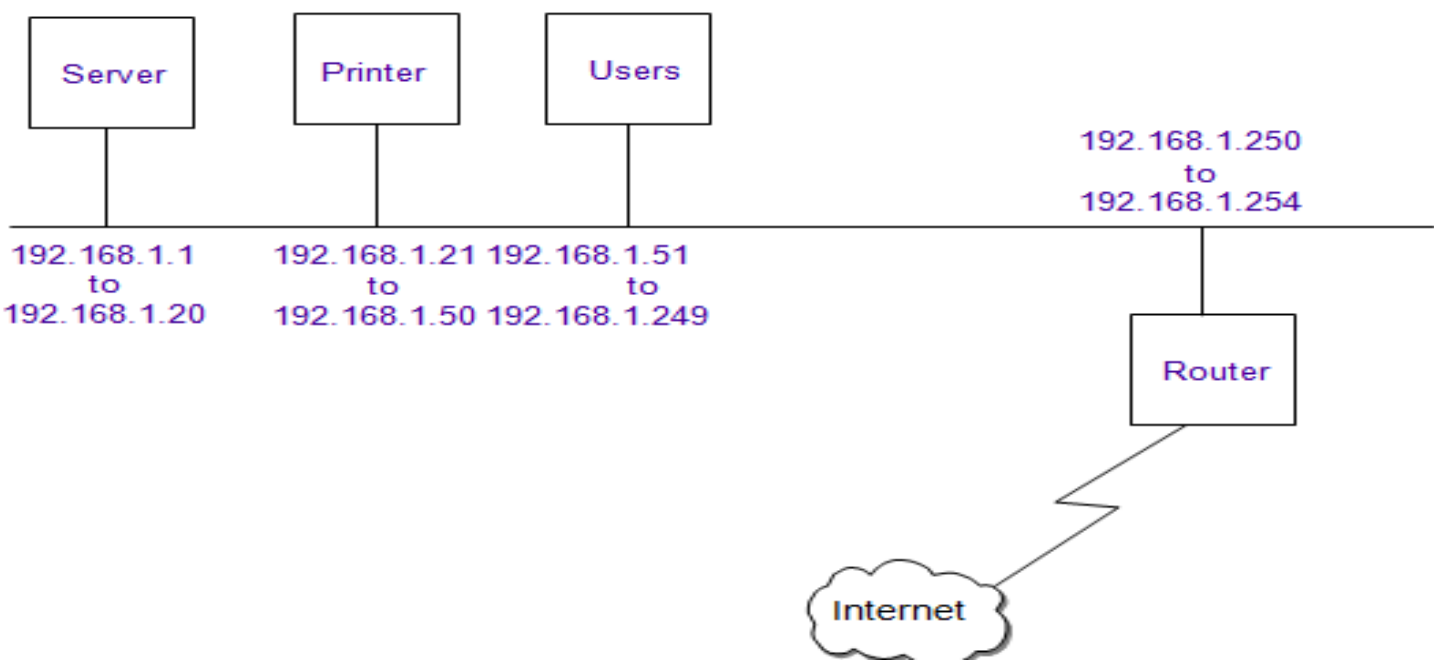

Fig. 7. Rational Network Design for a Small Network.

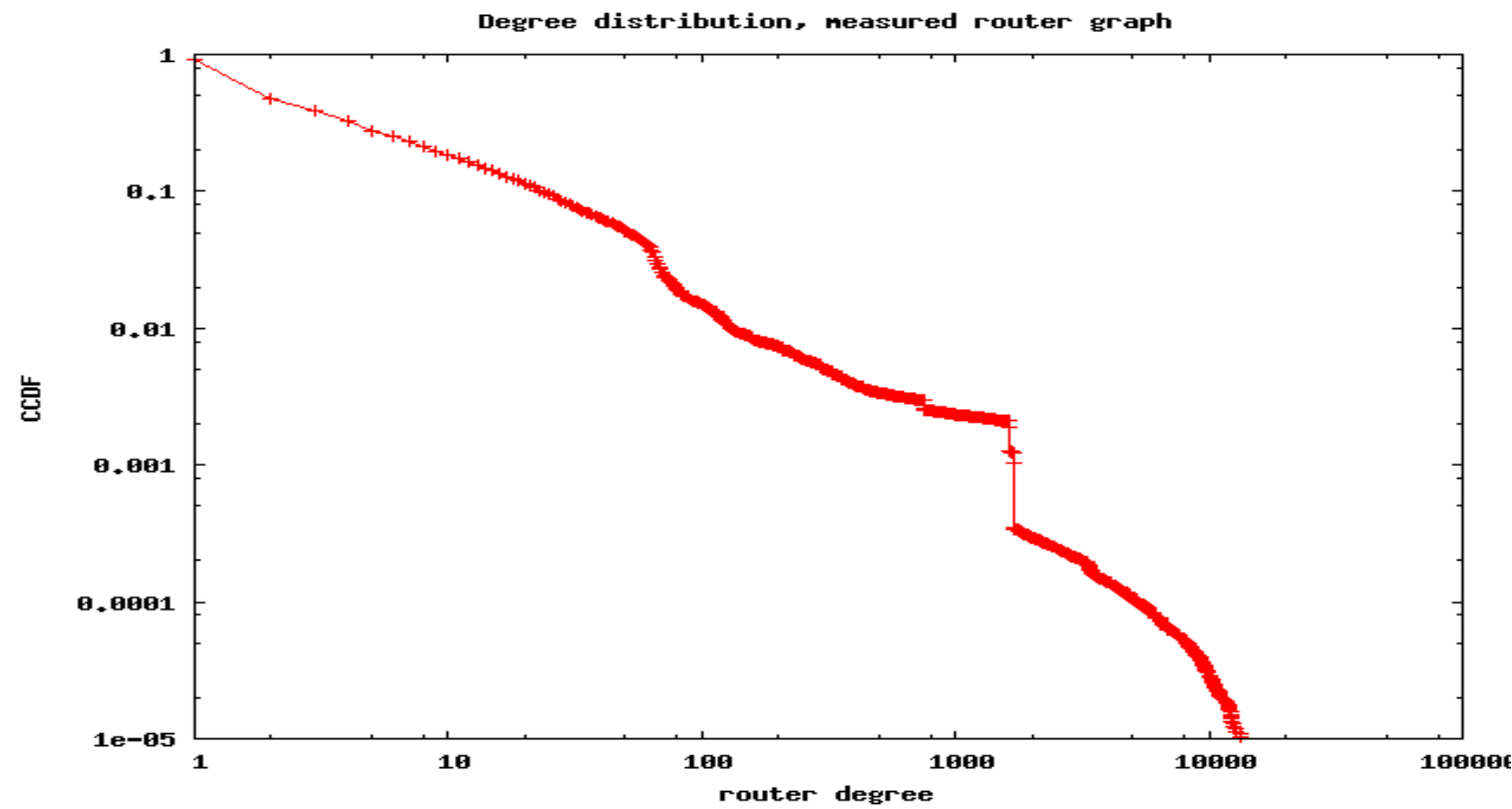

Fig. 8. Web geography at switch and AS-levels, and the double router+AS Internet geography generator.

\section{RESULT AND DISCUSSION}

In this paper, I got the best consequence of the most brief way from Basis to Endpoint is Link state Algorithm, for that the reports had sent from Basis to Endpoint is the least cost way, so the information has been sent extremely quick from Basis to Endpoint. When contrasted and different Algorithms, it has the technique to transmission the information from Start to Endpoint. OSPF (Open Shortest Way First) is a broadly utilized convention for the Internet directing utilizing the Dijkstra's Algorithm. Tear (Routing Info Protocol) is another directing based convention of Ford Algorithm. By fulfilling, these realities the information can degree its end point with no mistake in separation and heading. There are various kinds of trading: package, circuit, multilayer, virtual circuit, wide zone arrange (WAN), neighborhood (LAN). Circuiting and virtual circuit trading frequently suggest WAN or telephone progressions, and in that limit, won't be a bit of our discussion. Group trading when in doubt concerns a switch or perhaps a WAN switch. Multilayer trading is a technique for improving the treatment of IP bundles, anyway most merchants have different musings concerning the best philosophy. Routinely, LAN switches are passed on with no plan to how multilayer trading may improve execution. In reality, other than guiding between VLANs, directors are now and again fascinated by how top tier features might be used on the framework. Since this book is about IP-based frameworks organization, trading will regularly imply Ethernet diagrams and the coordinating will be that of IP packs.

\section{CONCLUSION}

Grounds frameworks have fascinating arrangement gauges that give progressively noticeable flexibility to help a wide extent of client devices and applications. Wired access, far off, and PoE contraptions exist together at the framework edge. Key client applications require high bandwidth, high openness, and security. A layered grounds orchestrate designing with fan-out to client devices at the passage layer, association of access layer traffic through the combination layer,

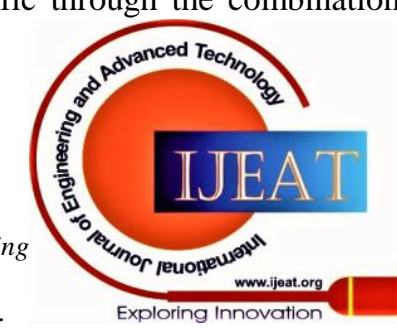




\section{Configure Routing Path Algorithms for Ethernet Topology}

and brought together directing through the framework place gives a flexible model to building up the grounds compose after some time and obliging higher traffic volumes and various shows, as required. The full set-up of Ruckus vigilant grounds mastermind IP structure game plans and comprehensive framework the administrators mechanical assemblies enable customers to develop and become incredible, monetarily insightful, and business-smoothed out grounds sorts out that meet both current and future corporate necessities.

\section{REFERENCES}

1. W Jo, S Kim, C Lee, T Shon, "Packet Preprocessing in CNN-Based Network Intrusion Detection System”, Electronics (2020).

2. Shin, Y Kim , H Yoo, D Kim, D Kang, “Digital Forensic Practices and Methodologies for AI Speaker Ecosystems. Digit. Investig”, 29, S80-S93.

3. http://www.cs.tau.ac.il/ eddiea/networkshop/IP-design.pdf

4. https://networkencyclopedia.com/frame-relay/

5. https://www.geeksforgeeks.org/a-search-algorithm/

6. https://en.wikipedia.org/wiki/Dijkstra\%27s_algorithm\#Algorithm

7. https://en.wikipedia.org/wiki/Link-state_routing_protocol

8. https://www.javatpoint.com/link-state-routing-algorithm

9. J. F. Kurose , K. W. Ross, “Computer Networking: A Top-Down Approach Featuring the Internet", 4th Edition, Addison-Wesley,Boston,2007. http://dx.doi.org/10.4236/cn.2012.42013

10. R. E. Moore, "Method and application of interval analy- sis", SIAM, Philadelphia, 1997. M. Delgado, J. L. Ver-A. Sengupta, T. K. Pal, "Theory and methodology on comparing interval numbers", European Journal of Op- erational Research, Vol. 127, 28-43,2000.doi:10.4236/wsn.2010.22020.

11. Carmo, M Sá Silva, J Monteiro, E Simões, and F Boavida, "Ethernet QoS Modeling in Emerging Scena- rios. Proceedings of 3rd International Workshop on Internet Performance, Simulation, Monitoring and Measurement", IPS-MoMe (2005), Warsaw, 14-15 March 2005,90-96.http://dx.doi.org/10.4236/jcc.2016.44006.

12. Salsano, S Detti, A Cancellieri, M Pomposini, and N Blefari-Melazzi, "Transport- Layer Issues in Infor- mation Centric Networks", Proceedings of the Second Edition of the ICN Workshop on Information-CentricNetworking,Helsinki, 17 August 2012, 19-24. http://dx.doi.org/10.1145/2342488.2342493.

13. S Salsano, Detti, A Cancellieri, M Pomposini, and N Blefari-Melazzi, " Transport- Layer Issues in Infor- mation Centric Networks", Proceedings of the Second Edition of the ICNWorkshop on Information-CentricNetworking, Helsinki, 17 August 2012, 19-24. http://dx.doi.org/10.1145/2342488.2342493.

14. P. Radoslavov et al., "On Characterizing Network Topologies and Analyzing Their Impact On Protocol Design”, Computer Science Department, University of Southern California,Tech. Rep.00-731, Feb. 2000.

15. S. Ratnasamy et al., "A Scalable Content Addressable Network", Proc. ACM SIGCOMM,Aug. 2001.

16. D. Stutzbach and R. Rejaie, "Capturing Accurate Snapshots of the Gnutella Network”, Proc.IEEE Global Internet Symp., Mar. 2005.

17. D. Stutzbach, R. Rejaie, and S. Sen, "Characterizing Unstructured Overlay Topologies in Modern p2p File-Sharing Systems", Proc. ACM SIGCOMM Internet Measurement Conf. (IMC),Oct.2005. doi : 10.1093/ietcom/e89-b.9.2300.

18. H. Burch and B. Cheswick, "Mapping the Internet", Computer, 32(4):97 \{98,102, 1999. doi : 10.1109/2.755008.

19. G. O. Young, "Synthetic structure of industrial plastics (Book style with paper title and editor)", in Plastics, 2nd ed. vol. 3, J. Peters, Ed. New York: McGraw-Hill, 1964, pp. 15-64.

20. W.-K. Chen, "Linear Networks and Systems", (Book style). Belmont, CA: Wadsworth, 1993, pp. 123-135.

21. H. Poor, "An Introduction to Signal Detection and Estimation", New York: Springer-Verlag, 1985, ch. 4.

\section{AUTHORS PROFILE}

I am R. Idayathulla, Assistant Professor, Department of Computer Science, PRIST,Puducherry Campus. I

have A Nine years of showing involvement with

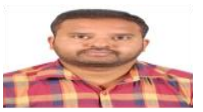

College.I am Pursuing PhD (Computer Science) at PRIST (Deemed To be University) at Thanjavur. I have an information on C, C++, Java, Oracle, Visual Basic, and SQL. My Area of Research work is Computer Networks.

I am Dr K. Saravanan M. Sc., M. Phil., M. S. M. Tech., Ph.D., Dean,

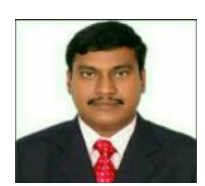
Faculty of ,Faculty of Computer Science, PRIST (Deemed to be University), Thanjavur. I had investigates in Data Mining, Algorithms.I had distributed a great deal of examination papers. I had distributed a ton of examination papers I had likewise remember an exploration for computational Algorithms. Beneficiary latest distribution is 'Improved Optimization centroid in changed Kmeans cluster.'• Sir Guide many examination Scholars to Guide a scientists.
Blue Eyes Intelligence Engineering and Sciences Publication (C) Copyright: All rights reserved.

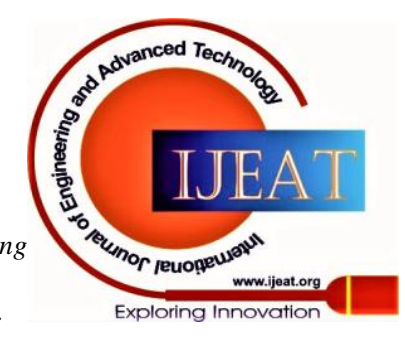

